\title{
INTRODUCING SIMULATION ACROSS THE DISCIPLINES
}

\author{
Charles R. Standridge \\ 301 West Fulton \\ School of Engineering \\ Padnos College of Engineering and Computing \\ Grand Valley State University \\ Grand Rapids, MI 49504 USA
}

Björn Johansson

Department of Product and Production Development

Chalmers University of Technology

Gothenburg, 412 96, SWEDEN

\author{
Martha A. Centeno \\ Industrial and Systems Engineering \\ Florida International University \\ Miami, FL 33199, USA
}

\author{
Ingolf Ståhl \\ Department of Managerial Economics \\ Stockholm School of Economics \\ S-11383 Stockholm, SWEDEN
}

\begin{abstract}
How to introduce simulation is a fundamental educational issue in a variety of disciplines including industrial engineering and operations management as well as product design and manufacturing. This panel will discuss, compare, and contrast various perspectives and experiences concerning introducing simulation to undergraduate and graduate students. Topics considered by the panel include the fundamental purposes of a first simulation course, modeling and analysis assignments that are given, examination topics, laboratory content, and term project experiences.
\end{abstract}

\section{CHARLES STANDRIDGE}

At Grand Valley State University, simulation is introduced to undergraduate and graduate students in the product design and manufacturing engineering program. Product design and manufacturing engineering is a relatively new discipline that spans the product development and production life cycle. Curriculum topics includes determining customer requirements, product design, materials and process selection, machine design, automated control systems, lean manufacturing, production systems organization, work environments, material handling, and supply chains. Simulation as well as optimization are seen as fundamental analysis tools to be applied in multiple topical areas.

Currently, students in the BSE and the MSE programs take essentially the same introductory simulation course. By the end of the course, students are expected to be able to use simulation in the design and analysis of production systems common in this area of lean manufacturing. Kan- ban systems and cellular manufacturing systems are emphasized. Issues involving both work-in-process (WIP) and finished goods inventories (FGI) are included. Setting resource levels, such as the number of machines at a station, to meet lead time requirements is discussed. Understanding worker movement in manufacturing cells is important.

Model building and experimentation are given equal emphasis. Simple analytic models are employed as part of simulation experimentation activities to set initial values for model parameters as well as for validation and verification. The minimum number of machines needed at a work station can be computed. Initial estimates of finished goods inventory levels as well as kanban levels can be computed. Work cell design and staff approaches are covered.

The following types of assignments are given:

- Software tutorials for one simulation environment and one distribution function fitting environment. The undergraduate students use ProModel and the graduate students use AutoMod.

- Exercises on the operation of the simulation engine and basic analysis of simulation results.

- Exercises on the use of simple analytic models.

- Case problems (Standridge 2000):

- Setting the number of machines in a job shop to meet lead time requirements.

- Establishing finished goods inventory levels and CONWIP levels. 
- Assessing the operation of a manufacturing cell, including worker movement within the cell.

- Industrial based term project.

The software tutorials and exercises each cover one technical aspect of the simulation process. In total, they prepare the student for performing the case studies and term project that follow.

The industrial based term project allows students the opportunity to take what they have learned in the class and apply it to problems at their place of employment. This is possible since co-operative education is mandatory for all undergraduate students and the vast majority of graduate students are employed full time in industry.

The case studies replace the mid-term examination given in a traditional course. The term project replaces the final examination.

The course is taught in a computer aided teaching (CAT) studio (Standridge 2001) so that lecture and laboratory activities can be mixed as necessary. Time is given during the scheduled class periods for work on the software tutorials, exercises, case problems, and term project. Thus, student interaction with the instructor is encouraged.

\section{MARTHA CENTENO}

The undergraduate program in Industrial and Systems Engineering at FIU has one course on simulation as part of its 3 course sequence in systems modeling and analysis, composed of deterministic O.R., Stochastic O.R., and the Simulation course. The simulation course is taken after the deterministic O.R. Course and could be taken before or after the stochastic O.R. course. The simulation course seeks to provide the industrial engineering students with an applied understanding of the role of modeling and simulation in the analysis of typical Industrial Engineering Systems, so that they are able to identify, analyze, and derive solutions to problems in a system. It also seeks to provide them with a basic understanding of discrete event simulation modeling and analysis procedures. In addition, students are made familiar with the extent of the real world use of simulation modeling by having students review a series of five or six articles published in the open literature. The topics of the course have been mapped around the macro steps of the simulation modeling process. Hence, the course has been broken down in modules: 1) theoretical modeling principles, 2) analysis of raw data to establish probabilistic input models, 3) practical methodology for conceptualizing and building simulation models, 4) verification and validation of simulation models, and 5) analysis of simulation results. All cases require a written technical report.

The concepts are first presented in a lecture mode, where examples from manufacturing and service systems are used to drive the point home; the lectures are followed by a hands-on lab activity. Fundamentals concepts such as the elements of a system (entities, activities, resources, and controls) are explained via specific sample systems with which students are familiar. Two sample systems are picked, based on the preferences of the class, as recurring examples for other concepts such as what kind of inputs are needed to build a simulation model, what kind of outputs would one desired out of the simulation experimentation, and so forth.

Four types of assignments are used to allow students to put into practice the concepts learned: 1) homework for model abstraction, 2) guided hands-on laboratories, 3) team case project, and 4) individual reading and summarizing of real world applications of simulation modeling.

The homework assignments for model abstraction are given during the first 3 weeks of the course, and are done on paper, with no implementation on any software. Students are given 5 to 7 different systems, and are asked to identify the various components and to establish what inputs they would need if they were to build a simulation model.

Guided laboratories are given once a week with a two fold objective: a) practice the concepts explained in the lectures and implement them using a commercial software package. At FIU, we have been using ARENA; however, students are made aware that the concepts are not software dependent. Five to six different sample systems are discussed in the labs and a model of each of them is built and run. The lab sessions are interactive in the sense that if the class thinks that an assumption needs to be removed are added, the lab practice is modified accordingly. If the class suggestions represent a major change to the lab objective, then an explanation is given as to the implications of it, and their suggestion is implemented only partially. The sample systems for which models are built are drawn mainly from manufacturing and service systems. In addition the lab assignments, students are encouraged to build models of the well defined systems that appear at the end of the chapters in their textbook; however, these are not submitted for grading.

This course does not require an actual industry project, but a significant number of Senior Design projects, which are industry projects, use simulation successfully. Instead of a project, there are three case studies assigned each semester. Students are teamed up in duos or trios, depending on the number of students in the class. Team composition is assigned for case 1, but students choose the composition for cases 2 and 3. The case resembles and industrial application, but is under controlled conditions. Students are given a statement describing a system about which management has some concerns. No clear objective of the simulation study is given as it is part of the practice stu- 
dents are expected to acquire. Each case emphasizes modeling and model building principles and one of three main activities: 1) analysis of inputs, verification and validation, and 3) analysis of outputs. Typically, students have 4 weeks to work on a case.

For the first case, minimal data is given with the system description. The team members are expected to brainstorm and decide what the goal of the simulation study should be, what assumptions to make, and what data they need. For about five of the activities in the problem system, the team would receive computer generated raw data, and they are expected to establish the probabilistic models using the appropriate goodness of fit techniques and ls. A step by step practice guide of ARENA's Input Analyzer and Experfit are made available to the entire class via the web, so they do not have to do the analysis all using Excel.

For the second case, most of the data is given to the student in the "plug-into-model" form. Depending on how well the class did in case one, sometimes it is necessary to have them do a couple of goodness of fit tests in case two to further strengthening their understanding of the concepts. Pseudo "real world" data is made available to the teams for one or two of the activities so that they can validate the model. Verification is done using empirical approaches such as walkthroughs. A step-by-step guide of ARENA's debugger is made available via the web.

For the third and last case, all data is given in the "plug-into-model" form. The emphasis is on the teams clearly identifying the boundaries of the simulation study (study's objectives experimental conditions), and on engaging in the analysis of the outputs and evaluation of alternatives. A step-by-step guide of ARENA's process analyzer and ARENA's Output analyzer is made available via the web.

Examinations are the most difficult part to prepare. In addition to the theory (definitions, etc.), students are expected to show understanding model abstraction and model building. The lab assignments and the cases are not enough to measure individual mastery of these skills. Hence, the three examinations (including he final), also have a model building problem. The graphical nature of ARENA has posed a challenge for this part. So, students are given the syntax of the text version of the blocks, and are asked to combine the graphical version of the blocks or modules with the text version. The model building problem is graded more looking for the skill of model building using ARENA, and not for syntax.

\section{BJÖRN JOHANSSON}

The primary target for our introductory course on manufacturing systems, where we discuss discrete event simulation for the first time, is to make the students aware of the potential of discrete event simulation for analyzing the $d y$ - namics of a manufacturing system. The students will after this short introduction (approximately 4 hours total) have "ordering-competence", i.e. know where to find experts on discrete event simulation and what kind of problems they are capable of solving. They will also have an understanding regarding the requirements for conducting discrete event simulation projects.

The second contact with discrete event simulation is in the simulation course, which has its main focus on discrete event simulation $(90 \%)$, and some smaller guest lectures on for example assembly simulation, robot simulation, metal cutting simulation, fluid dynamics simulation, manikin simulation etc... 2 hours each (which totals to about $10 \%)$.

This discrete event simulation course has the primary objective set higher: The students will understand the potentials, setbacks and requirements on discrete event simulation of manufacturing systems. They will also have basic skills in discrete event simulation project methodology, data collection, coding, modeling, statistical distributions, verification, validation, experimental design and analysis of output data. Additionally the students will have the knowledge to manage discrete event simulation projects including being a competent player in the actual execution of the project.

We (Department of Product and Production Development at Chalmers University of Technology) use Automod, which comes with a large "tutorial manual" named Getting started with Automod (Banks 2004). Getting started with Automod is used as a base for voluntary homework.

The examination is made in two steps (in the simulation course).

Firstly we have a small written classroom exam on the basics of simulation, where we check if the student did actually listen when participating in class. It will consist of about five to ten questions on basic discrete event simulation, such as:

- Describe the methodology used when conducting a discrete event simulation project.

- What is the difference between Verification and Validation of a DES model.

- Describe five potentials which can be achieved when utilizing discrete event simulation for manufacturing systems.

- Describe five traps during the conduction of a discrete event simulation project, and how to avoid them.

- $\quad$ Etc.....

Secondly we have a large discrete event simulation project; time for the project is approx 5 weeks. This project is conducted in pairs of students. The project follows the classical discrete event simulation project methodologies 
described by such as Banks (2004), Law and Kelton (2000), Pedgen et al (1995).

The students get information on how the manufacturing system is characterized and all needed input data. Additionally they get a list of investment cost for improving the facility and a budget of $\$ 150000$. In short, the task then is to:

1. make a project plan

2. model the factory

3. make an experimental plan
(a) find the bottleneck
(b) eliminate it
(c) iterate until the budget is used up

4. write a project report

After each week, we have checkpoints to follow up each project, in order to see that all pairs are on track and will be able to finish the project on time.

The evaluations of the course do have very high grades from the students especially on the project part. But they do on the same time say that the course is very, very time consuming and hard.

(From my point of view as a teacher I can see a connection on time spent and amount of knowledge achieved!!)

We use one simple variant of a laboratory exercise in the manufacturing systems course.

This exercise is conducted as follows:

1. Collecting input data (Cycle times, buffer sizes, number of pallets used in the system) from a real world laboratory conveyor system

2. Put the collected data into a predefined model made in Automod

3. Run the model and analyze output data

4. Find the bottleneck

5. Suggest actions taken in order to increase the system output

6. Change the model accordingly (with help from a laboratory assistant)

7. Run the model and analyze output data

8. Compare with previous run

9. Conclude

During the simulation course we use another laboratory exercise, which aims more at solving manufacturing system related problems, such as bottleneck detection, buffer balancing, resetting problems, and routing problems. A laboratory task is described. After that we have some (35) two hour computer room lectures with laboratory assistants attending to help on the task. This exercise is mainly made out of two purposes:
1. Getting to know the simulation package (in this case Automod) before taking on the large project described above on point 3 .

2. Understanding the dynamics of manufacturing systems, including coping with the problems without investing in new machines.

3. Several, about twenty per year, master of science students who takes the simulation course do also try to find a master thesis project (project duration 20 weeks) within the field of discrete event simulation. Some of these projects can be found as part of case studies in papers presented at previous Winter Simulation Conferences (Johansson and Kaiser 2002, Johansson et al 2003).

\section{INGOLF STÅHL}

I shall here talk about how I how been teaching simulation to over 7000 business students in Sweden, Norway and the US since the mid-70s. I have mainly been teaching simulation in three different forms:

1. As a small part (2-4 hours) of a Management Science, or introductory computer, course, aiming at a rapid introduction to simulation.

2. As a ten hour part of a course on computer methods, presenting the main ideas of simulation modeling.

3. A full forty hour course, going slightly beyond the technical material under point 2 above, but involving a substantial simulation project.

There are some common objectives for these three different courses. A basic goal for all is to give our business students at least some idea about discrete event simulation, by using a simulation package. It should be stressed that our business students generally have no knowledge of computer programming and have only had some introductory statistics. Our focus is hence on creating informed buyers of simulation services. Some knowledge of simulation modeling is e.g. important for making reasonably realistic time assessments of the work of a simulation specialist. Knowledge of simulation is also important for being able to "sell" the idea of making a larger simulation project to top-management.

Furthermore, in the courses with at least ten hours, we have aimed at giving our students enough simulation knowledge to be able to do some rapid prototyping, which can sometimes be used directly as a "quick-and-dirty" model to solve an immediate problem or be the basis for discussions with simulation experts when producing an extended simulation model. 
I furthermore think that simulation also has some specific issues to bring to the mind of the business student:

Simulation can replace, or at least complement, other Management Science methods, such as queuing theory, inventory theory, PERT/CPM and decision analysis (Ståhl 2005). Our students have appreciated this, since this has implied a greater focus on solving problems and fewer methods to be learnt (and forgotten).

Our students need understanding of the physical flows that constitute the reality behind the financial flows and of the importance of manufacturing. Simulation is one way of giving business students an introductory understanding of some problems in the areas of production economics, material handling, inventory management, etc. Closely connected to this is the demonstration of the connection between the physical activities and the consequential financial flows.

It should be mentioned that we have in all three types of courses used a simulation package and allowed the students to do some modeling on their own. It is my belief that as long as at least two full classroom hours are available, one should try to teach some basic simulation modeling. This is better than a very broad overview, without any "hands on" experience. A student can get some idea about both the potentials and restrictions of simulation only by doing some kind of simulation modeling..This will also make simulation fun. Our students have done interesting things, in the form of non-trivial simulation programs, after only a very short period of learning.

After two hours our students model "Joe's barbershop", producing full queuing statistics, including also histograms (Born and Ståhl, 2004). By varying the parameters of uncertainty, the students can study the effect of uncertainty on queuing behavior. After four hours they simulate "Boris vodka shop", which produces surprising and revealing statistics on queuing behavior (Ståhl 2000).

After ten hours, the students do, as the main part of the examination, a simulation model of a small furniture company, based on a real case study (Ståhl 1996). This model involves decisions on production, inventory and planning and produces profit/loss accounts and balance sheets as well as graphs of the development of cash. The students make several runs to insure both good profitability and a low probability of bankruptcy.

In the forty hour course, usually with the first ten hours almost the same as in the preceding paragraph, I also make the students work through the whole simulation process as regards some concrete problem, usually in business. In this way, the student can actively learn the whole process, from delimiting the problem, formulating the question to be answered, gathering data, outlining the model graphically, coding the program, verifying, validating and documenting, running the program a sufficient number of times, doing a statistical analysis for drawing significant conclu- sions, and presenting the results in a form suitable for a potential user, with a focus on implementation.

The students first make a reasonably valid simulation model of the present set-up. They gather input data (on items like arrival, service and waiting times) from the real system and then compare the output data (e.g. on waiting) from the tentative model with this real data. Finally, the students provide and test a suggestion for an improvement of the system. This project determines the main part of the grade of the course.

I have in such courses had good experience of students, in groups of two or three, doing project work in different corporations, for example in banking, telecommunications and retailing. Some projects have dealt with "sales support simulation models", where the simulation model is run on a laptop and the program is run interactively with a client, regarding e.g. the optimal configuration of a corporate telephone exchange system. Many of the project programs have had continued use in the corporations and some students have been hired on the basis of such a project.

All my teaching has been done in computer labs. I have found this important, since I can then be assured that the students have understood the mechanics of the simulation system. The students will here, under my supervisions, also solve exercises of gradually increasing complexity.

We have in all courses used the WebGPSS (or microGPSS) package. WebGPSS is a stream-lined, GUI and Web based, version of GPSS, developed gradually over 25 years, mainly on the basis of feedback obtained from 7000 students. In the process, many complicated and redundant syntax features have been eliminated. Thus WebGPSS has only 18 block types, compared to the 70+ block types of other GPSS versions. Thanks to these simplifications, we now cover in ten hours the same material that required 22 hours with "old" GPSS. Yet WebGPSS is almost as powerful. We have rewritten 99 percent of the programs in leading GPSS textbooks with the same amount of code.

WebGPSS is presented in Ståhl (2003). It is available on the Web at <Www. webgpss.com/ENG>. There is also a stand-alone version on a CD. WebGPSS is supplemented with program examples, a score of tutorial lessons and a large set of help pages. We have selected WebGPSS since the short time needed to learn this system leaves a lot of time in the full course to spend on e.g. the issues of collection and evaluation of input data, the principles of experimental design, statistical analysis of the output, aspects of implementation, etc., i.e. issues left out in many courses where most time is spent on a difficult-to-learn simulation system.

\section{REFERENCES}

Banks, J. 2004. Getting started with AutoMod, $2^{\text {nd }}$ edition. Chelmsford, MA: Brooks Automation. 
Born, R. and I. Ståhl. 2004. WebGPSS -the first hours of simulation education. Stockholm: SSE.

Johansson, B., Johnsson, J., Kinnander A., 2003. Information structure to support discrete event simulation projects, in Proceedings of the 2003 Winter Simulation Conference, ed. S. Chick, P. J. Sánchez, D. Ferrin, and D. J. Morrice, 1290-1295, Institute of Electrical and Electronics Engineers, Piscataway, NJ.

Johansson, B., Kaiser, J., 2002. Turn lost production into profit -discrete event simulation applied on resetting performance in manufacturing systems, in Proceedings of the 2002 Winter Simulation Conference, ed. E. Yücesan, C.-H. Chen, J. L. Snowdon, and J. M. Charnes, 1065-1072, Institute of Electrical and Electronics Engineers, Piscataway, NJ.

Law, A. M. and W. D. Kelton. 2000. Simulation modeling and analysis, $3^{\text {rd }}$ edition. New York: McGraw-Hill.

Pegden, C. D., Shannon, R.E., Sadowski, R.P., 1995. Introduction to simulation Using SIMAN, 2nd Ed., New York: McGraw-Hill.

Ståhl, I. 1996. Simulation of the business operations of a small furniture company. in Modelling and simulation ESM96, ed. A. Javor, A. Lehmann \& I. Molnar, 374376. Budapest: SCS.

Ståhl, I. 2000. How should we teach simulation? In Proceedings of the 2000 Winter Simulation Conference, ed. J. Joines, R. Barton, K. Kang and P. Fishwick, 16021612. New York: ACM.

Ståhl, I. 2003. Simulation made simple with webgpss $-a$ tutorial. Stockholm: SSE.

Ståhl, I. 2005. Using discrete event simulation in the teaching of decision analysis. In Proceedings of the 2005 Winter Simulation Conference, ed. M. E. Kuhl, N. M. Steiger, F. B. Armstrong, and J. A. Joines. New York: ACM.

Standridge, C. R., 2000. Teaching simulation using case studies. In Proceedings of the 2000 Winter Simulation Conference, ed., J. A. Joines, R. R. Barton, K. Kang, and P. A. Fishwick, 1630-1634. Institute of Electrical and Electronics Engineers, Piscataway, NJ.

Standridge, C. R., 2001. Teaching manufacturing systems simulation in a computer aided teaching studio. In Proceedings of the 2001 Winter Simulation Conference, ed., B. A. Peters, J. S. Smith, D. J. Mederios, and M. W. Rohrer, 1613-1618. Institute of Electrical and Electronics Engineers, Piscataway, NJ.

\section{BIOGRAPHIES}

CHARLES R. STANDRIDGE is a professor in the School of Engineering, Padnos College of Engineering and Computing, at Grand Valley State University. He has over 30 years of simulation experience in academia and industry. He has performed many simulation applications, de- veloped commercial simulation software, and taught simulation at three universities. His current research interests are in the development of simulation cases management systems (SCMS). He is working with industry on the application of SCMS to lean manufacturing problems particularly inventory control and logistics. His teaching interests are in the concurrent use factory physics, lean manufacturing, and simulation in introductory undergraduate and graduate courses using a case-based approach. He also teaches in the area of engineering measurement and data analysis. He has a Ph.D. in Industrial Engineering from Purdue University. His email address is $<$ standric@grsu.edu> .

MARTHA A. CENTENO is an associate professor in the Department of Industrial and Systems Engineering at Florida International University. She has a B.S. in Chemical Engineering from ITESO University (Guadalajara, Mexico), a M.S. in Industrial Engineering from LSU (Baton Rouge, LA), and a Ph.D. in Industrial Engineering from Texas A\&M University (College Station, TX). Her current research interests are in the design and development of integrated simulation systems, on-line goal driven simulation, and the integration of operations research techniques and simulation. She is a member of Tau Beta Pi, Alpha Pi $\mathrm{Mu}$, Phi Eta Sigma, Omega Rho, Phi Kappa Phi, Phi Beta Delta, IIE, and INFORMS. Her email address is $<$ centeno@fiu.edu>.

BJÖRN JOHANSSON was born in Gothenburg, Sweden, 1975. He attended Chalmers University of Technology at Mechanical Engineering, where he obtained his $\mathrm{PhD}$ degree in 2005 . He is currently working as a research assistant in the field of Discrete Event Simulation and Modular Manufacturing Systems at the Department of Product and Production Development, Chalmers University of Technology, Gothenburg, Sweden. His email address is $<$ Bjorn. Johansson@me. chalmers.se>.

INGOLF STÅHL is a Professor at the Stockholm School of Economics, Stockholm, and has a chair in Computer Based Applications of Economic Theory. He was visiting Professor, Hofstra University, N.Y., 1983-1985. He has taught GPSS for thirty years at universities and colleges in Sweden, Norway and the USA. Based on this, he has developed the micro-GPSS and WebGPSS systems. His email address is <ingolf.stahl@hhs.se> and the web address for WebGPSS is <www . webgps. . com/ENG>. 